\title{
Green synthesis of iron nanoparticles using aqueous extract of Turbinaria conoides (J. Agardh) and their anticancer properties
}

\author{
Asha D. V. Bensy, G. Johnsi Christobel \\ Department of Botany and Research Centre, Nesamony Memorial Christian College, Marthandam-629165, \\ Tamil Nadu, India
}

Received: December 07, 2020 Revised: February 18, 2021 Accepted: March 04, 2021 Published: April 13, 2021

*Corresponding Author: G. Johnsi Christobel Email: johnsichristobel@gmail. com

\section{ABSTRACT}

Marine macroalgae produce numerous bioactive compounds with potential pharmacological properties. In this study, macroalga was collected from the Gulf of Mannar, India and identified as, Turbinaria conoides (J. Agardh). The aqueous extract of T. conoides was used to synthesize iron nanoparticles (NPs). The synthesized iron NPs were characterized by X -ray diffraction analysis, Scanning Electron Microscopy, and Transmission Electron Microscopy. The synthesized NPs showed potent activity against DLDl and HeLa cell lines.

KEYWORDS: Green synthesis, seaweed, Turbinaria conoides, anticancer

\section{INTRODUCTION}

Seaweeds are considered as the source of various bioactive compounds as they are able to synthesize potential secondary metabolites (Smit, 2004) characterized by various biological activities including, antibacterial, antiviral and anticancer activities (Chakraborthy et al., 2010). Anti tumour and antifungal activities were detected in red, brown and green algae. The antimicrobial property of seaweed mainly based on algal species, extraction method and solvents used for extraction. However, maximum bioactive potential was obtained from the dried macroalgae samples than fresh algal samples and have been reported previously by various research groups (Manivannan et al., 2011). Seaweeds contain a wide variety of numerous bioactive compounds offering a potential source of novel drugs with very low toxicity (Ganesan et al., 2020). Sample preparation, extraction method and processing greatly affected the bioactivity of macroalgae (Moraes-de-Souza et al., 2008). Many findings showed that a rich of dietary intake of various natural phenols with the presence of various types of antioxidants such as, phenols and flavonoids generally found in seaweeds and plants is mainly associated with reduced risk of developing chronic diseases, longer life expectancy, and various types of cancer. The present investigation aimed to analyze in vitro antioxidant, antibacterial activity and characterization of iron oxide nanoparticles using Turbinaria conoides (J. Agardh) collected from Gulf of Mannar, Tamilnadu, India.

\section{MATERIALS AND METHODS}

\section{Collection of Seaweed and Identification}

The seaweed was collected during the study period (July 2018 December 2018) by manually and detaching a portion from the sea bed, exposed rock surfaces of rocky coast in Gulf of Mannar, Tamilnadu, India. The samples were cleaned thoroughly to remove debris. The seaweed was identified as Turbinaria conoides (J. Agardh) using the manual authenticated by Botanical Survey of India (BSI/SRC/5/23/2020/Tech/885).

\section{Preparation of Seaweed Extract}

$10 \mathrm{~g}$ air dried powder was weighed and transferred in $100 \mathrm{ml}$ solvent such as, methanol, chloroform, acetone, ethyl acetate and ethanol for $24 \mathrm{~h}$. The Erlenmeyer flask was kept on an orbital shaker at $150-200 \mathrm{rpm}$ for $24 \mathrm{~h}$. Then the sample was filtered using a Whatman's No. 1 filter paper. The filtrates were further evaporated under reduced pressure and semi-solid material was obtained with the help of rotary evaporator. The dried residue was further stored in a plastic vials. The extraction procedure was repeated three times.

Copyright: (C) The authors. This article is open access and licensed under the terms of the Creative Commons Attribution License (http://creativecommons.org/licenses/by/4.0/) which permits unrestricted, use, distribution and reproduction in any medium, or format for any purpose, even commercially provided the work is properly cited. Attribution — You must give appropriate credit, provide a link to the license, and indicate if changes were made. 


\section{Green Synthesis of Iron Nanoparticles}

$100 \mathrm{~g}$ fresh seaweed was ground using a pestle and mortar and microwave assisted extraction was performed using a microwave oven. The extract was filtered and stored at $4{ }^{\circ} \mathrm{C}$ and used for the green synthesis of Fe NPs. Ferrous sulphate was prepared at $1 \mathrm{mM}$ concentration and aqueous extract of was added in drop wise manner with continuous stirring. Reduction reaction was stopped after brownish black colour formation and it was incubated at $32 \pm 2{ }^{\circ} \mathrm{C}$ for $4 \mathrm{~h}$. Iron oxide NPs was then isolated from the solution by evaporating water on a hot plate dried for overnight using a dryer. The synthesized NPs were purified by refluxing using Milli $Q$ water followed by absolute ethanol.

\section{Characterization of NPs}

The colour change of $\mathrm{FeCl}_{3}$ solution $(100 \mathrm{~mL})(1 \mathrm{mM})$ after the addition of alga extract $(1 \mathrm{~m})$ from yellowish-brown to black was confirmed the synthesis of iron oxide NPs. It was dispersed in distilled water and the spectrum was analyzed between of 200-800 nm using a UV-visible spectrophotometer. $\mathrm{X}$-ray diffraction of iron oxide NPs was performed using Philips X'Pert Pro instrument. The iron NPs was scanned within the 2 Theta range of 20-80 Theta angle. The surface structure was characterized using SEM JEOL-MODEL 6390 wafter coating on copper grid for $5 \mathrm{~min}$ on mercury lamp. The shape and size of the iron NPs was evaluated by Transmission Electron Microscopy (TEM).

\section{Anticancer Activity Analysis}

Green synthesized NPs were used for the determination of anticancer activity.DLD-1 (Human Colorectal Adenocarcinoma) cells and HeLa (cervical cancer cells) were initially procured from National Centre for Cell Sciences (NCCS), Pune, India. It was maintained in Dulbecco's modified Eagles medium (DMEM). Then the cells were cultured in $25 \mathrm{~cm}^{2}$ tissue culture flask with DMEM supplemented with sodium bicarbonate, L-glutamine and 10\% FBS (Merck, Germany) and antibiotics. Cell lines were kept in a humidified $\mathrm{CO}_{2}$ incubator at $37^{\circ} \mathrm{C}$. After $24 \mathrm{~h}$ the tissue culture medium was removed and NPs were added at various concentrations $(100 \mu \mathrm{g}, 50 \mu \mathrm{g}, 25 \mu \mathrm{g}$, $12.5 \mu \mathrm{g}, 6.25 \mu \mathrm{g}$ in $500 \mu \mathrm{l}$ of DMEM). It was further incubated in a humidified $5 \% \mathrm{CO}_{2}$ incubator at $37^{\circ} \mathrm{C}$. The morphological changes were detected using an inverted phase contrast tissue culture microscope. The percentage viability was calculated using the following formula. \% of viability = Mean OD Samples x 100/ Mean OD of control group.

\section{RESULTS AND DISCUSSION}

\section{T. conoides Extract and Biological Activity}

Marine macroalgae produce various bioactive compounds with potential pharmacological properties. These organisms produce various compounds in response to the characteristics as well as environmental condition. In this study, a potential macroalga was collected from Gulf of Mannar, India and identified as, T. conoides (J. Agardh) (Figure 1). Seaweeds have been widely recognized as potential producers of an enormous range of compounds with bioactive potential compounds. However the activity of the same genus or species could vary depending on the geographical locations due to seasonal and environmental parameters (Chakraborthy et al., 2010).

\section{Characterization of Iron NPs}

An absorption range from $200 \mathrm{~nm}$ (near the Ultra violet) to $800 \mathrm{~nm}$ (in the very near to infra-red) was clearly observed in the sample. In Figure 2, the peaks are high between 200 and $300 \mathrm{~nm}$ indicated the reduction of iron oxide. X-ray diffraction analysis provides valuable information on crystalline structure, average grain size, preferred crystal orientations, phases and crystal defects. The present finding revealed that T. conoides showed the wide intensities for the determination of atomic positions in the lattice (Figure 3). XRD peaks are generally obtained by constructive interference of a monochromatic beam of X-rays scattered at specific angles from each set of lattice planes in a sample. Generally, online search tool for X-ray powder diffraction patterns enables quick phase identification for the identification of various samples. Figure 4 clearly revealed that the presence of green synthesized iron NPs in the sample. The SEM images made possible the visualization

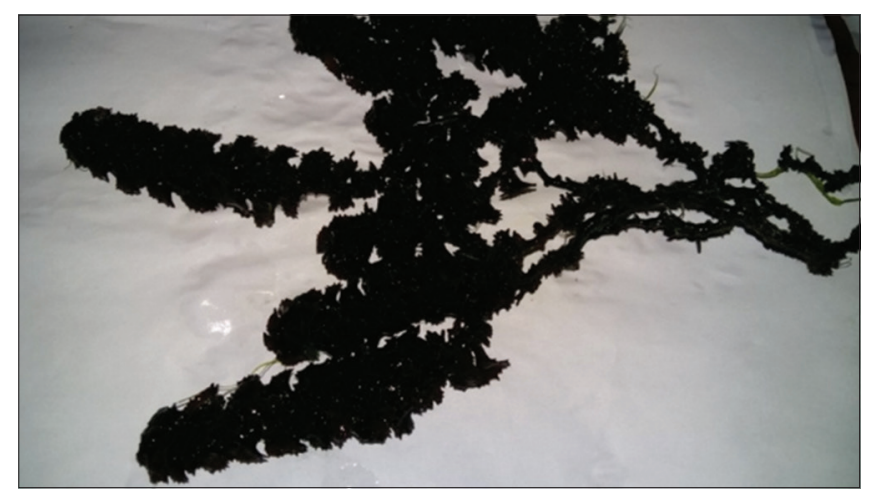

Figure 1: Appearance of T. conoides collected from Gulf of Mannar, Tamilnadu India

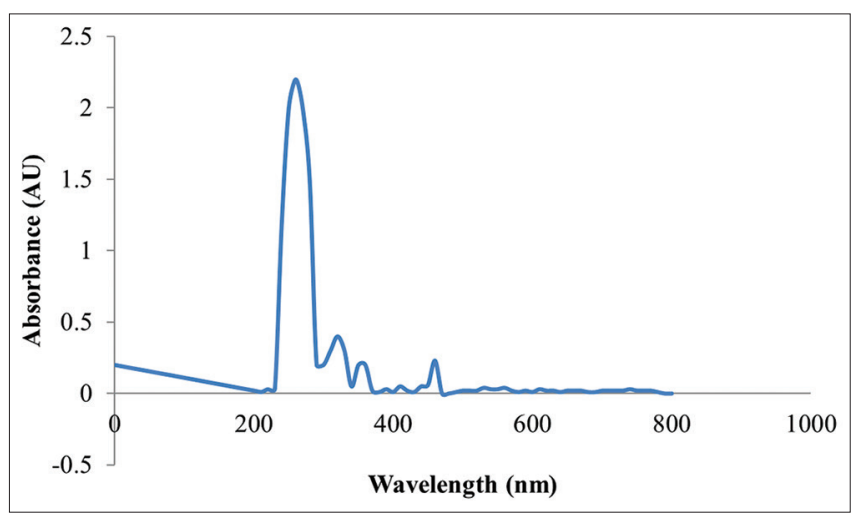

Figure 2: UV spectroscopy analysis of green synthesized iron NPs using $T$. conoides extract 


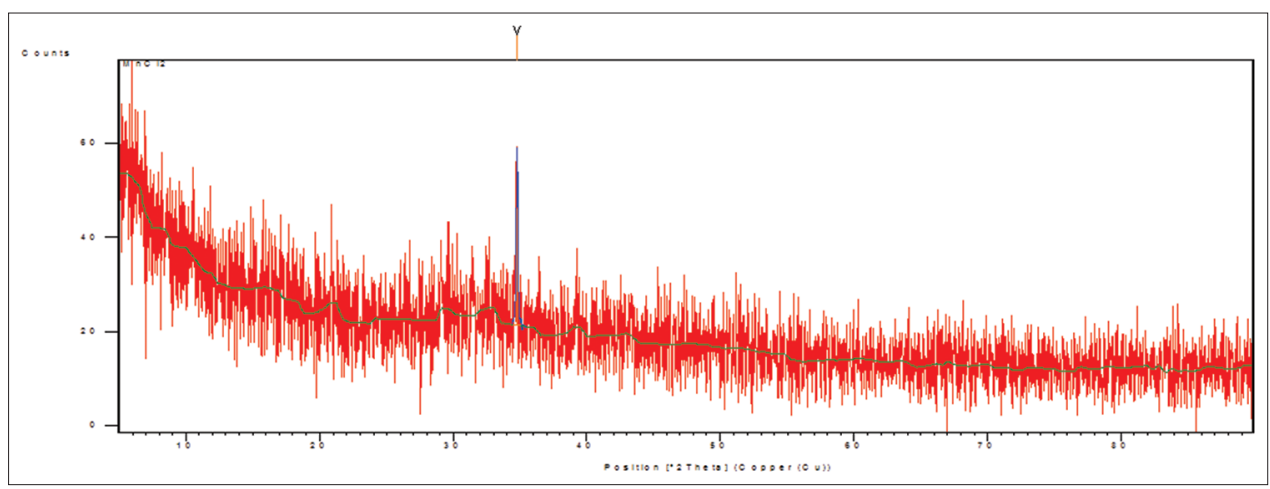

Figure 3: XRD of iron NPs green synthesized using T. conoides extract

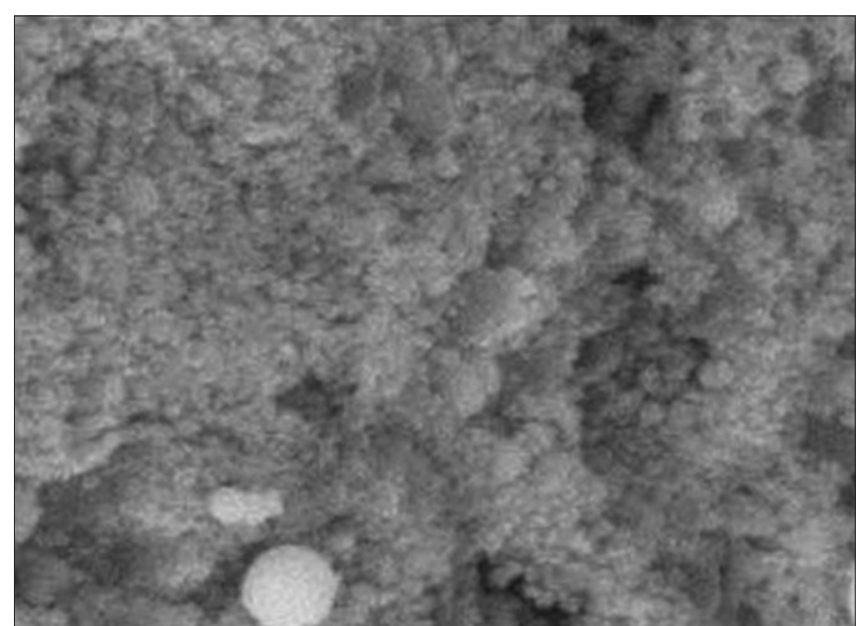

Figure 4: Scanning Electron Microscopy analysis of iron NPs green synthesized using $T$. conoides extract

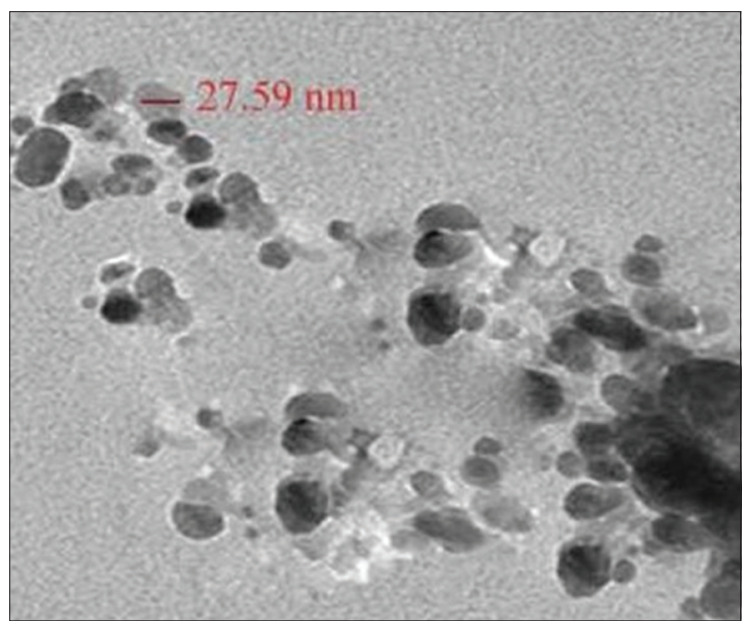

Figure 5: Transmission Electron Microscopy image of iron NPs green synthesized using $T$. conoides

of the morphology of the NPs and to determine the size of NPs. TEM analysis clearly revealed the presence of NPs with $27.59 \mathrm{~nm}$ size (Figure 5). Macro algae are important sources of phytochemicals involved in the biosynthesis of types of metallic NPs. Macro algae such as, Stoechospermum marginatum, Laminaria japonica, Turbinaria conoides, and

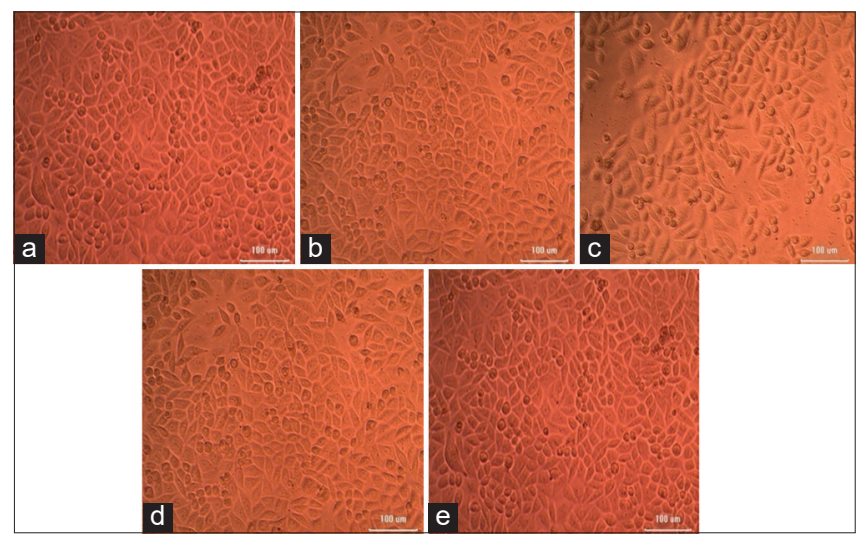

Figure 6: Anticancer activity of iron NPs synthesized using T. conoides against HeLa cell lines

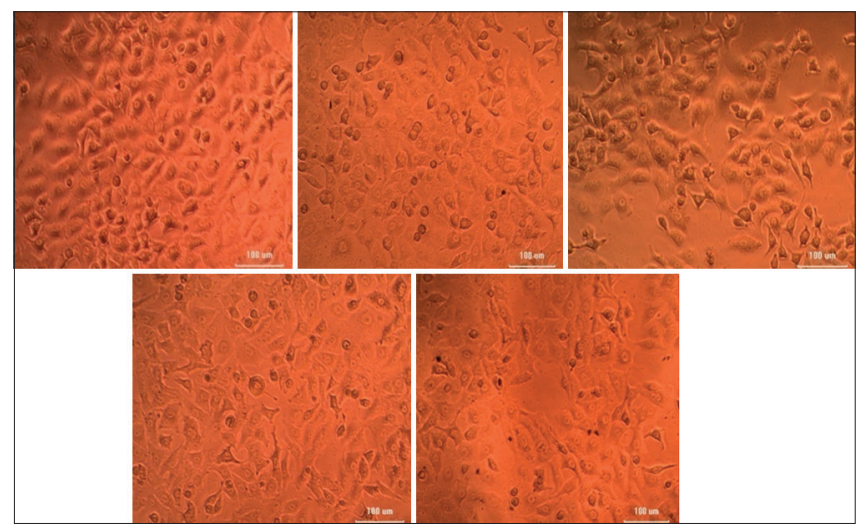

Figure 7: Anticancer activity of green synthesized iron NPs against DLD1cell lines

Sargassum wightii (Singaravelu et al., 2007; Ghodake and Lee, 2011; Rajathi et al., 2012). Green synthesis of iron NPs was initially characterized by colour formation from yellowishbrown to black in the mixture and showed surface plasmon resonance band was centered at $240-320 \mathrm{~nm}$ showed the presence of iron NPs. SEM and TEM analysis revealed the morphology and crystalline structure of green synthesized NPs and the NPs size range of 27 to $30 \mathrm{~nm}$. Recently, El-Kassas et al. (2016) used Sargassum acinarium (Linnaeus) and Padina pavonica (Linnaeus) for the biosynthesis of iron oxide NPs. 
Table 1: Viability of HeLa and DLDl cell lines treated with iron NPs at various concentrations.

\begin{tabular}{lcc}
\hline Sample Concentration $(\mu \mathrm{g} / \mathrm{mL})$ & \multicolumn{2}{c}{ Viability (\%) } \\
\cline { 2 - 3 } & HeLa & DLD1 \\
\hline Control & 100 & 100 \\
6.25 & 90.35 & 91.22 \\
12.5 & 85.44 & 79.07 \\
25 & 79.49 & 68.82 \\
50 & 51.35 & 60.21 \\
100 & 26.41 & 27.28 \\
\hline
\end{tabular}

\section{Anticancer activity of iron NPs}

MTT assay is frequently used to evaluate the NPs to determine proliferative or cell toxicity activity. The LC-50 value was found to be $157.366 \mu \mathrm{g} / \mathrm{mL}$ and results indicated that NPs had significant activity against HeLa and DLDl cell lines and the results were depicted in Table 1. Anticancer activity of iron NPs synthesized using T. conoides against HeLa and DLDlcell lines was described in Figures 6 and 7. Any new drug required cytotoxic analysis in cancer cell and cell viability test is determined under microscope (Arasu et al., 2019). In MTT assay, the linear relationship between colour produced and metabolic process of active cells and useful for the determination of the rate of proliferation or cell death. SEM and TEM analysis was employed to study the morphological and structural features of synthesized FeNPs. SEM and TEM analysis revealed uniform, spherical shaped NPs within $30 \mathrm{~nm}$ size. In this study, some of the larger particles were identified due to aggregation of NPs because of evaporation of alcohol during the preparation of samples. This kind of NPs aggregation has been reported previously. XRD analysis clearly indicated the presence of metallic silver nanocrystals due to surface plasmon resonance. The intense signals between 2 and $4 \mathrm{KeV}$ indicated the presence of metallic nanocrystals (Singaravelu et al., 2007). The synthesized nanoparticles have the ability to inhibit the growth of cell lines HeLa and DIDl. The anticancer activity of nanoparticles has been reported previously (Valsalam et al., 2019; Arasu et al., 2019; Venkatadri et al., 2020; Lydia et al., 2020; Malar et al., 2020).

\section{CONCLUSION}

The aqueous extract of $T$. conoides was used to synthesize iron NPs. The present finding eliminates the wide use of various chemical substances as stabilizing and reducing agent. Because sea weed has various chemical constituents which are polyphenolic substances and fucoidan, it shows a dual application as both stabilizing and reducing agent for iron NPs. The synthesized NPs showed potent activity against DLDl and HeLa cell lines.

\section{REFERENCES}

Arasu, M.V., Arokiyaraj, S., Viayaraghavan, P., Kumar, T.S.J., Duraipandiyan, V., Al-Dhabi, N.A., \& Kaviyarasu, K. (2019). One step green synthesis of larvicidal, and azo dye degrading antibacterial nanoparticles by response surface methodology. Journal of Photochemistry and Photobiology B: Biology, 190, 154-162. https://doi.org/10.1016/j. jphotobiol.2018.11.020

Arasu, M.V., Madankumar, A., Theerthagiri, J., Salla, S., Prabu, S., Kim, H.S., Al-Dhabi, N.A., Arokiyaraj, S., \& Duraipandiyan, V. (2019). Synthesis and characterization of $\mathrm{ZnO}$ nanoflakes anchored carbon nanoplates for antioxidant and anticancer activity in MCF7 cell lines. Materia/s Science and Engineering: C, 102, 536-540. https://doi.org/10.1016/j. msec.2019.04.068

Bindhu, M.R., Umadevi, M., Esmail, G.A., Al-Dhabi, N.A., \& Arasu, M.V. (2020). Green synthesis and characterization of silver nanoparticles from Moringa oleifera flower and assessment of antimicrobial and sensing properties. Journal of Photochemistry and Photobiology B: Biology, 205, 111836. https://doi.org/10.1016/j. jphotobiol.2020.111836

Campos-Takaki, G.M., Diu, M.B.S., Koening, M.L., \& Pereira, E.C. (1988), Screening of marine algae from Brazilian northeastern coast for antimicrobial activity. Botanica Marina, 31, 375-377. https://doi. org/10.1515/botm.1988.31.5.375

Chakraborthy, K., Lipton, A.P., Paulraj, R., \& Vijayan, K.K. (2010). Antibacterial diterpernoids of U/vafasciataDelile from South-western coast of Indian Peninsula. Food Chemistry, 119, 1399-1408. https://doi.org/10.1016/j. foodchem.2009.09.019

El-Kassas, H.Y., Aly-Eldeen, M.A., \& Gharib, S.M. (2016). Green synthesis of iron oxide (Fe3O4) nanoparticles using two selected brown seaweeds: characterization and application for lead bioremediation. Acta Oceanologica Sinica, 35(8), 89-98.

Ganesan, A.R., Mohanram, M.S.G., Balasubramanian, B., Kim, I.H., Seedevi, P., Mohan, K., Kanagasabai, S., Arasu, M.V., Al-Dhabi, N.A., \& Ignacimuthu, S. (2020). Marine invertebrates' proteins: A recent update on functional property. Journal of King Saud University-Science, 32(2), 1496-1502. https://doi.org/10.1016/i.jksus.2019.12.003

Ghodake, G., \& Lee, D.S. (2011). Biological synthesis of gold nanoparticles using the aqueous extract of the brown algae Laminaria japonica. Journal of Nanoelectronics and Optoelectronics, 6, 1-4. https://doi. org/10.1166/jno.2011.1166

Lydia, D.E., Khusro, A., Immanuel, P., Esmail, G.A., Al-Dhabi, N.A., \& Arasu, M.V. (2020). Photo-activated synthesis and characterization of gold nanoparticles from Punica granatum L. seed oil: An assessment on antioxidant and anticancer properties for functional yoghurt nutraceuticals. Journal of Photochemistry and Photobiology B: Biology, 206, 111868. https://doi.org/10.1016/j.jphotobiol.2020.111868

Malar, T.J., Antonyswamy, J., Vijayaraghavan, P., Kim, Y.O., Al-Ghamdi, A.A., Elshikh, M.S., Hatamleh, A.A., Al-Dosary, M.A., Na, S.W., \& Kim, H.J. (2020). In-vitro phytochemical and pharmacological bio-efficacy studies on Azadirachta indica A. Juss and Melia azedarach Linn for anticancer activity. Saudi Journal of Biological Sciences, 27(2), 682688. https://doi.org/10.1016/j.sjbs.2019.11.024

Manivannan, K., Karthikaidevi, G., Anantharaman, P., \& Balasubramanian, T. (2011). Antimicrobial potential of selected brown seaweeds from Vedalai coastal waters, Gulf of Mannar. Asian Pacific Journal of Tropical Biomedicine 1, 114-120. https://doi.org/10.1016/S22211691(11)60007-5

Moraes-de-Souza, R.A., Oldoni, T.L.C., Regitano-d'Acre, M.A.B., \& Alencar, S.M. (2008). Antioxidant activity and phenolic composition of herbal infusions consumed in Brazil. CYTA Journal of Food, 6(1), 41-47. https://doi.org/10.1080/11358120809487626

Rajathi, F.A.A., Parthiban, C., Ganesh Kumar, V., \& Anantharaman, P. (2012), Biosynthesis of antibacterial gold nanoparticles using brown alga, Stoechospermum marginatum (kützing). Spectrochimica Acta Part A Molecular and Biomolecular Spectroscopy, 99, 166-173. https://doi. org/10.1016/j.saa.2012.08.081

Salvador, N., Gómez Garreta, A., Lavelli, L., \& Ribera, M.A. (2007) Antimicrobial activity of Iberian macroalgae. Scientia Marina, 71, 101-114. https://doi.org/10.3989/scimar.2007.71n1101

Singaravelu, G., Arockiyamari, J., Ganesh Kumar, V., \& Govindaraju, K. (2007). A novel extracellular biosynthesis of monodisperse gold nanoparticles using marine algae, Sargassum wightii Greville. Colloids and Surfaces B: Biointerfaces, 57, 97-101. https://doi.org/10.1016/j. colsurfb.2007.01.010

Smit, A.J., (2004). Medicinal and pharmaceutical uses of seaweed natural products. A review. Journal of Applied and Phycology, 16, 245-262. https://doi.org/10.1023/B:JAPH.0000047783.36600.ef

Valsalam, S., Agastian, P., Arasu, M.V., Al-Dhabi, N.A., Ghilan, A.K.M., Kaviyarasu, K., Ravindran, B., Chang, S.W., \& Arokiyaraj, S. (2019). Rapid biosynthesis and characterization of silver nanoparticles 
from the leaf extract of Tropaeolum majus $L$. and its enhanced invitro antibacterial, antifungal, antioxidant and anticancer properties. Journal of Photochemistry and Photobiology B: Biology, 191, 65-74. https://doi.org/10.1016/j.jphotobiol.2018.12.010

Venkatadri, B., Shanparvish, E., Rameshkumar, M.R., Arasu, M.V., Al-Dhabi,
N.A., Ponnusamy, V.K., \& Agastian, P. (2020). Green synthesis of silver nanoparticles using aqueous rhizome extract of Zingiber officinale and Curcuma longa: In-vitro anti-cancer potential on human colon carcinoma HT-29 cells. Saudi Journal of Biological Sciences, 27(11), 2980-2986. https://doi.org/10.1016/j.sjbs.2020.09.021 